\title{
Correction to: A literature review on police patrolling problems
}

\author{
Sukanya Samanta ${ }^{1} \cdot$ Goutam Sen $^{2}$ D . Soumya Kanti Ghosh ${ }^{3}$ \\ Published online: 8 July 2021 \\ (c) Springer Science+Business Media, LLC, part of Springer Nature 2021
}

\section{Correction to: Annals of Operations Research https://doi.org/10.1007/s10479-021-04167-0}

This correction is published as author missed out critical corrections related with referencing style.

The article files have now been corrected.

Publisher's Note Springer Nature remains neutral with regard to jurisdictional claims in published maps and institutional affiliations.

The original article can be found online at https://doi.org/10.1007/s10479-021-04167-0.

Goutam Sen

gsen@iem.iitkgp.ac.in

1 Advanced Technology Development Centre, Indian Institute of Technology Kharagpur, Kharagpur, West Bengal 721302, India

2 Department of Industrial and Systems Engineering, Indian Institute of Technology Kharagpur, Kharagpur, West Bengal 721302, India

3 Department of Computer Science and Engineering, Indian Institute of Technology, Kharagpur, Kharagpur, West Bengal 721302, India 